\title{
EVALUATION OF COMMERCIAL-OFF-THE-SHELF LITHIUM BATTERIES FOR USE IN BALLISTIC TELEMETRY SYSTEMS
}

\author{
Edward F. Bukowski \\ U.S. Army Research Laboratory \\ Weapons and Materials Research Directorate \\ Aberdeen Proving Ground, Maryland \\ ebukowsk@arl.army.mil
}

\begin{abstract}
As technological advances continue to be made in the commercial sectors of portable and wireless communication products, additional advancements in battery technology have also been made. These advancements have allowed for the rapid growth of a large variety of commercially available batteries which have the capability to meet or even exceed the current power and size requirements for numerous ballistic telemetry systems. The replacement of a custom built battery with a COTS battery would provide immediate advantages such as lower cost, shorter lead times and higher availability. The overall objective of this paper is to provide ballistic telemetry systems engineers and designers with multiple low cost, readily available alternatives to traditional custom made power sources.
\end{abstract}

\section{KEYWORDS}

Telemetry, High-G, Batteries, Lithium Manganese Dioxide 


\section{INTRODUCTION}

In an effort to decrease the high cost and long lead times associated with developing custom batteries for use in ballistic telemetry systems, several commercial-off-the-shelf (COTS) batteries were evaluated to see if they would be a suitable alternative. In the past, specialized batteries were needed because commercially available batteries could not meet the size, power, and / or environmental requirements of a ballistic telemetry system. These specialized batteries were typically very expensive and took several months to be designed, fabricated, and tested. The use of a COTS battery would greatly decrease all of these factors. Several different battery chemistries, such as Alkaline, Lithium Thionyl Chloride, Nickel Metal Hydride, Nickel Cadmium, Lithium Manganese Dioxide, Lithium Ion and Lithium Ion Polymer were taken into consideration. This paper will present the results obtained from tests performed on a series of Lithium Manganese Dioxide cylindrical cells.

After reviewing all of the available cylindrical cells, the 123 and CR2 models were chosen for testing. They can typically be found in any store which sells portable electronic devices and their high capacities, small size, long shelf life and high availability make them ideal candidates. In an effort to limit the possible design differences between manufacturers, samples were taken from the Duracell ${ }^{\circledR}$ and Energizer ${ }^{\circledR}$ brands for these tests.

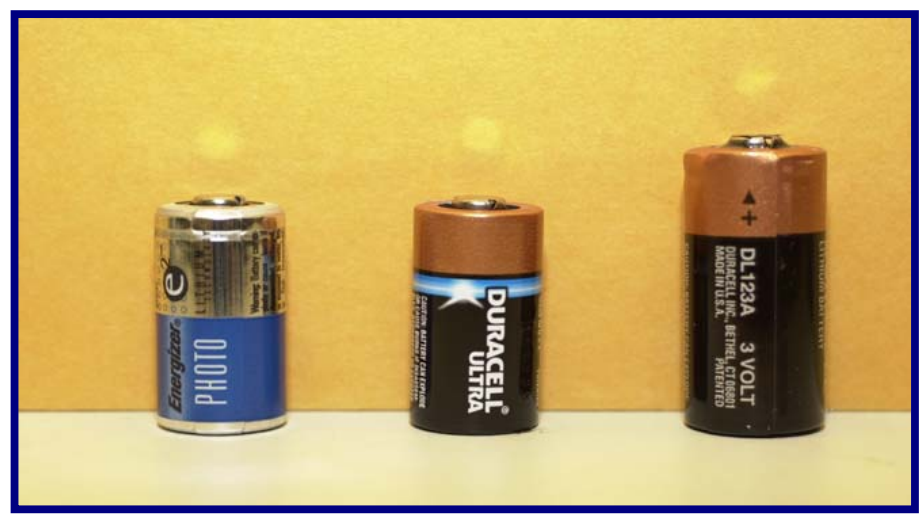

Figure 1: EL1CR2, DLCR2 and DL123 Lithium Manganese Dioxide Cylindrical Cells

\begin{tabular}{|r|c|c|c|}
\cline { 2 - 4 } \multicolumn{1}{c|}{} & EL1CR2 & DLCR2 & DL123A \\
\hline Nominal Voltage (volts) & 3.0 & 3.0 & 3.0 \\
\hline Rated Capacity (mAh) & 800 & 800 & 1500 \\
\hline $\begin{array}{r}\text { Max Discharge (mA) } \\
\text { continuous } \\
\text { pulse }\end{array}$ & 1000 & 1000 & 1500 \\
diameter & 15.6 & 2500 & 5000 \\
\hline height & 27.0 & 15.6 & 17.0 \\
\hline Dimensions (mm) & 11 & 11 & 34.5 \\
\hline Weight (grams) & & 17 \\
\hline
\end{tabular}

Table 1: Specifications for CR2 and 123 model cells 


\section{PRELIMINARY ELECTRICAL TESTING}

Individual cells were discharged at ambient temperature to determine a typical runtime at various levels of current draw. The CR2 cells were only discharged up to 1 amp since that was their maximum recommended level of discharge. Results from these tests produced runtimes from 25 minutes up to 2 hours. Since the majority of the projectile telemetry systems being developed by the Advanced Munitions Concepts Branch (AMCB) of the US Army Research Laboratory typically have a required runtime of 30 minutes and draw anywhere from $200 \mathrm{~mA}$ to $600 \mathrm{~mA}$, results from these preliminary tests show that both the CR2 and 123 cells are more than adequate to power these systems.

\begin{tabular}{|c|c|c|c|}
\hline \multirow{2}{*}{$\begin{array}{c}\text { Current } \\
\text { Draw (mA) }\end{array}$} & \multicolumn{3}{|c|}{ Typical Runtime to 2.0V Cutoff (minutes) } \\
\cline { 4 - 4 } EL1CR2 & DLCR2 & DL123A \\
\hline 500 & 85.07 & 92.07 & 140.75 \\
\hline 725 & 48.45 & 56.42 & 95.10 \\
\hline 1000 & 25.73 & 28.87 & 60.43 \\
\hline 1200 & N/A & N/A & 46.42 \\
\hline
\end{tabular}

Table 2: Room temperature $\left(\approx 20^{\circ} \mathrm{C}\right)$ discharge results for individual CR2 and 123 cells

Since the cells performed very well at ambient temperature, additional testing was conducted to determine performance at lower temperatures. The results from these tests, shown in table 3 , showed a significant drop in runtime from ambient temperature and that discharge currents higher than 500mA could not be achieved. As an example, at $500 \mathrm{~mA}$ and $-20^{\circ} \mathrm{C}$, the DLCR2 had an $82 \%$ decrease in runtime and the EL1CR2 had a $74 \%$ decrease in runtime. At $500 \mathrm{~mA}$ and $-40^{\circ} \mathrm{C}$, both cells lasted less than a minute and had a $99 \%$ decrease in runtime from ambient. Even though the cells performed poorly under the higher discharge rates, they still performed reasonably well under lower discharge rates. Therefore it is recommended that applications requiring low temperature performance only use these cells if the required current draw is limited to 250 to $350 \mathrm{~mA}$. It may be possible to increase performance by decreasing the cutoff voltage to $1.5 \mathrm{~V}$ per cell or using identical cells in parallel. However, this would be application specific and further testing would be necessary before implementation.

\begin{tabular}{|c|c|c|c|}
\hline \multirow{2}{*}{ Temperature } & $\begin{array}{c}\text { Discharge } \\
\text { Current (mA) }\end{array}$ & \multicolumn{2}{|c|}{$\begin{array}{c}\text { Runtime to 2.0V Cutoff (minutes) } \\
\text { DLCR2 }\end{array}$} \\
\hline \multirow{2}{*}{$-\mathbf{2 0} 0^{\circ} \mathbf{C}$} & 350 & 35.30 & 55.42 \\
\cline { 2 - 4 } & 500 & 16.55 & 21.87 \\
\hline \multirow{3}{*}{$-\mathbf{4 0} \mathbf{C}$} & 200 & 15.23 & 11.00 \\
\cline { 2 - 4 } & 250 & 6.10 & 6.48 \\
\cline { 2 - 4 } & 350 & 1.27 & 2.35 \\
\cline { 2 - 4 } & 500 & 28 seconds & 53 seconds \\
\hline
\end{tabular}

Table 3: Low temperature discharge results for CR2 cells 


\section{HIGH-G SHOCK TESTING}

One of the most important questions when designing for a ballistic telemetry system is whether or not the selected components will survive the harsh environmental conditions. Gun fired munitions often obtain acceleration levels anywhere from 10,000G's to over 100,000G's. All components used in an electronic system for these projectiles must be qualified to survive those types of accelerations. Mechanical components such as batteries are often susceptible to high shock levels based on cell construction, orientation and support. In an effort to increase the probability of success, each cell was encapsulated before testing. Encapsulation of components is a common practice in ballistic telemetry systems and is used to promote component survivability. In this case, the encapsulant should give extra vertical support and improve the overall integrity of the cell.

Multiple shock tests were performed on both the 123 and CR2 cells while mounted in both vertical, figure 2 , and horizontal, figure 3 , orientations. The cell voltage was monitored for each test and different loads were applied to simulate an active electronic system. Ideally, the cell potential should not change throughout the duration of the shock pulse. Each cell was then discharged post shock and the experimental results compared to the expected results.

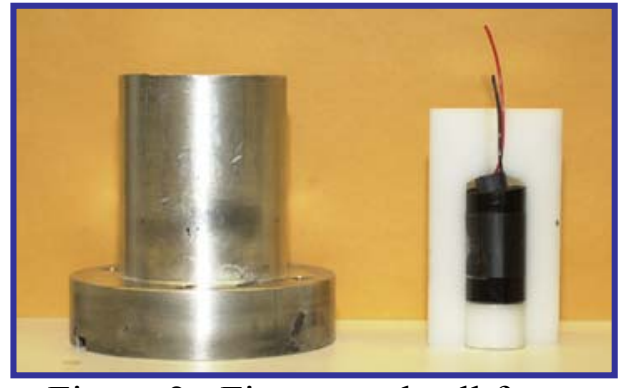

Figure 2: Fixture and cell for vertical shock testing

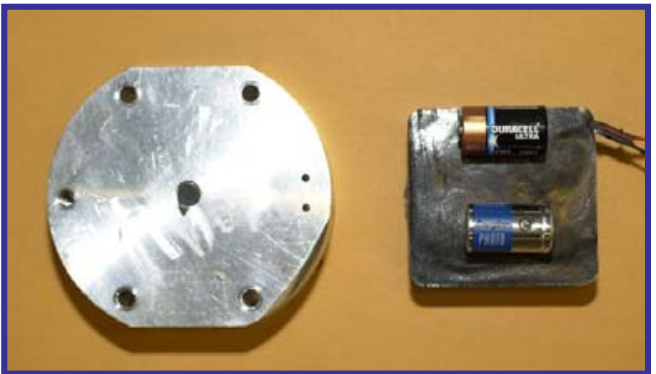

Figure 3: Fixture and cells for horizontal shock testing

The first set of testing was performed on both the CR2 and 123 cells in a vertical orientation. The ARL high-G impact table was used to obtain acceleration levels between 10kG's and $35 \mathrm{kG}$ 's for these tests. The test set included three DL123A cells, four DLCR2 cells and four EL1CR2 cells. Test results, some of which are shown in figures 4 and 5, showed that all three of the DL123A cells had major dropouts during the impact event and failed shock testing. No further tests were conducted with the 123 cells because of these failures.

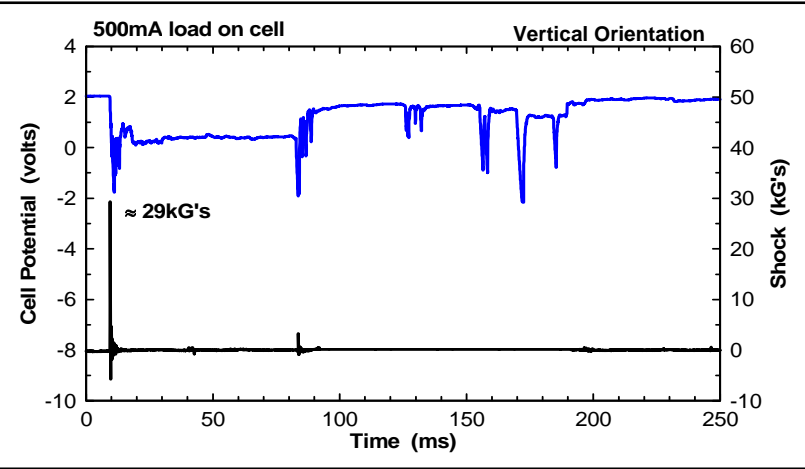

Figure 4: Test results for DL123 cell \#2

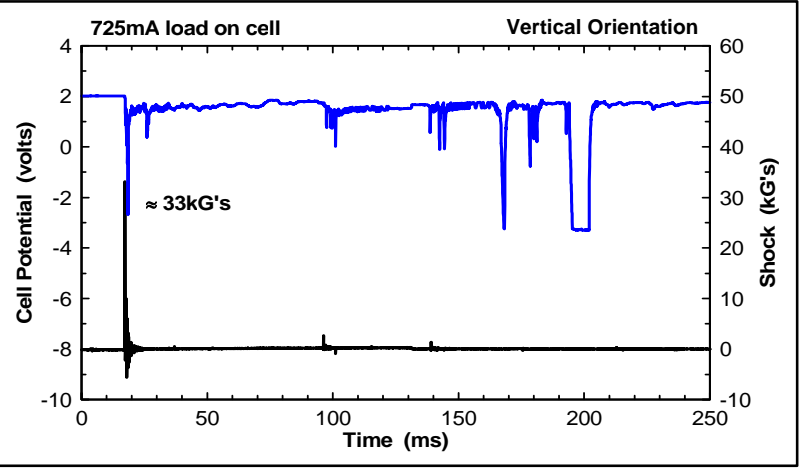

Figure 5: Test results for DL123 cell \#3 
Test results for the CR2 cells showed that the cell voltage remained almost constant, less than $50 \mathrm{mV}$ change, throughout the impact event. Each cell was shock tested 2 to 3 times apiece and the results were typical of those shown in figures 6 and 7. Post shock discharge tests showed that the impact event had no lasting effect on the cells. A comparison of discharges of the shock tested cells with an untested control cell is shown in figures 8 and 9 .

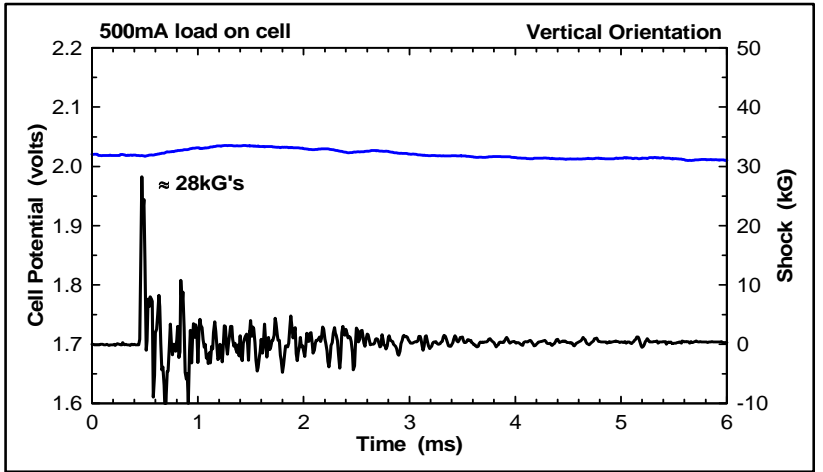

Figure 6: DLCR2 cell \#3 - shock test \#2

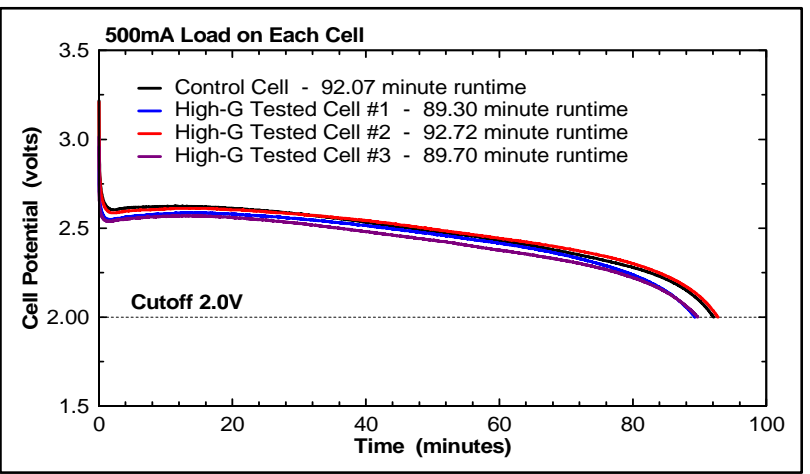

Figure 8: DLCR2 post shock discharges

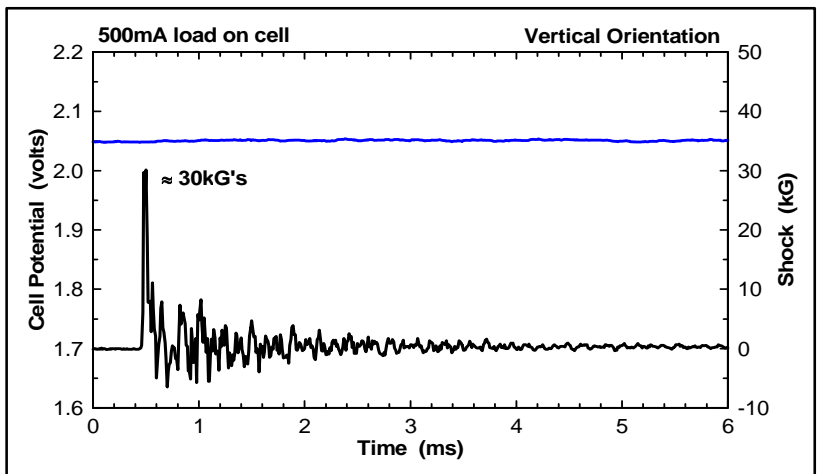

Figure 7: EL1CR2 cell \#3 - shock test \#2

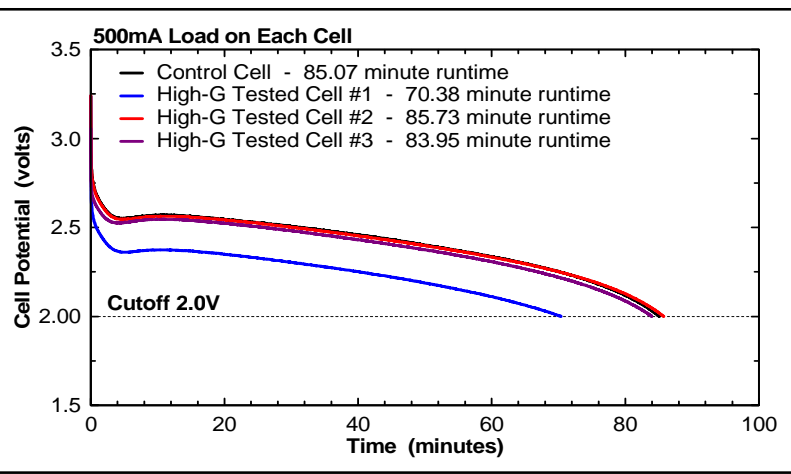

Figure 9: EL1CR2 post shock discharges

After successfully surviving high-G accelerations up to 35kG's in a vertical orientation, shock testing was continued with the CR2 cells mounted in a horizontal orientation. An identical test plan was followed with the cells being tested both with and without a load applied and then electrically discharged afterward. The only other difference between these tests and the previous ones, aside from cell orientation, was that the cells were tested two at a time for these tests. A sample space of two DLCR2 cells and two EL1CR2 cells were used for these tests. Each cell was shocked twice and then discharged. Once again, the cells performed very well under high-G conditions and the results were typical of those in figures 10 and 11. Post shock discharge curves were once again very similar to the discharge curve of an untested control cell. However, there was more of a decrease in runtime and amplitude between the tested and untested cells in this case. This does show that the cells tested in the horizontal orientation had some lasting effects from the high acceleration testing. However, the shapes of the discharge curves are still representative of a typical discharge and the runtimes are also still well within acceptable limits. A comparison of discharges of the shock tested cells with an untested control cell is shown in figures 12 and 13. 


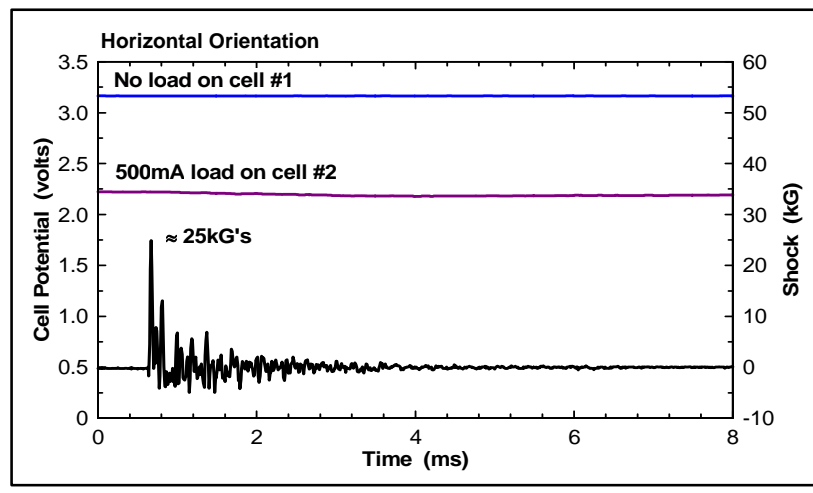

Figure 10: DLCR2 cells 1 \& 2 - shock test \#1

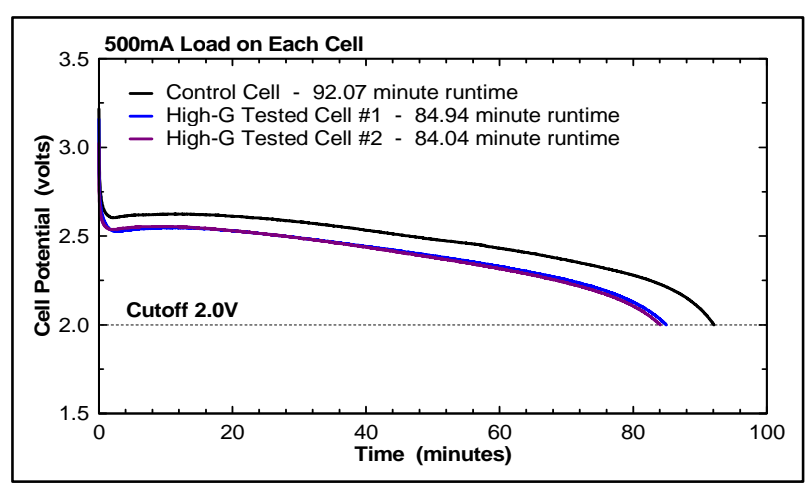

Figure 12: DLCR2 post shock discharges

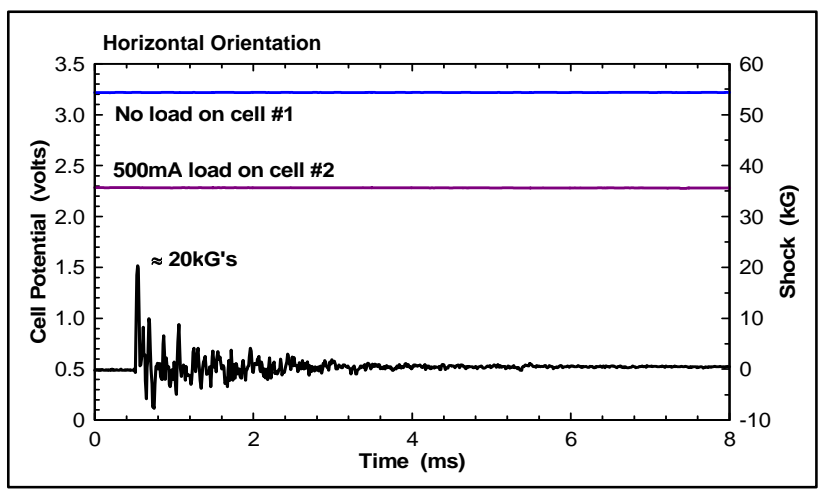

Figure 11: EL1CR2 cells 1 \& 2 - shock test \#1

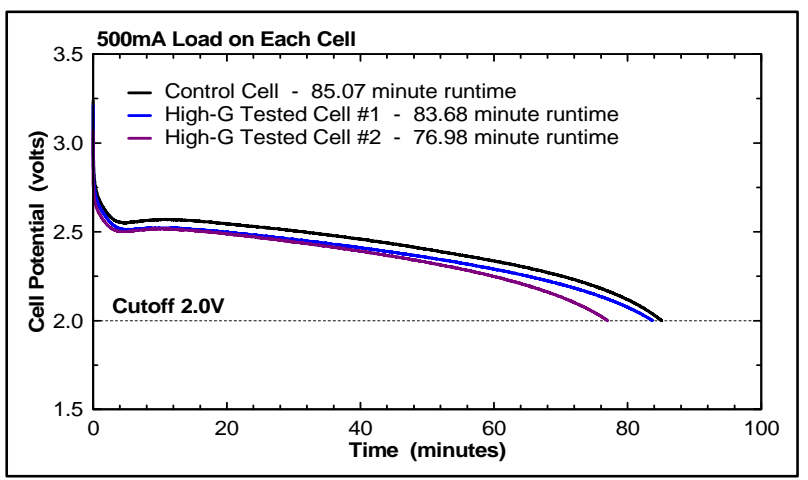

Figure 13: EL1CR2 post shock discharges

The shock testing completed up to this point has been performed on an impact shock test machine capable of achieving accelerations up to $35 \mathrm{kG}$ 's. Based on the excellent CR2 shock test results obtained so far, additional testing was performed at acceleration levels up to 100kG's. Since the impact shock test machine could not reach these levels, the 4" airgun located at the ARL Adelphi facility was used. The airgun provides acceleration pulses which are not only higher in amplitude, but also longer in duration (500 to $1000 \mu$ s depending on acceleration level)

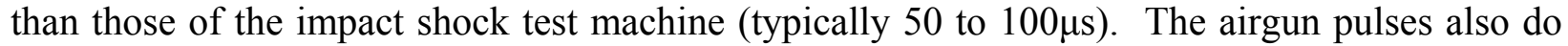
not have the high frequency content seen in the pulses obtained from the impact shock test machine. The only drawback to using this system was that the cells tested could not be monitored during the impact event. Therefore, all of the cells were flown without a load applied and post shock discharge results were compared to those of a control cell.

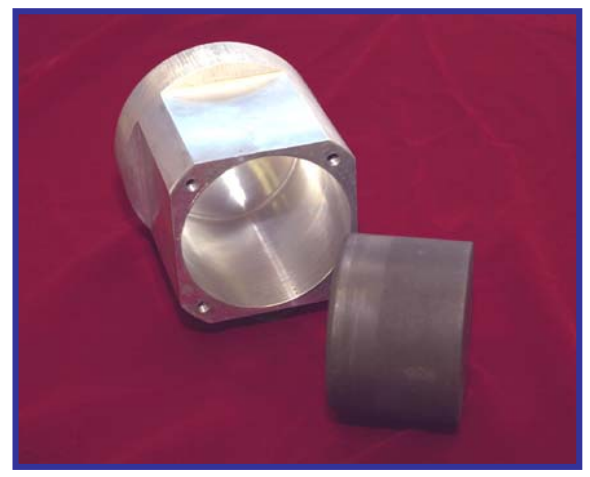

Figure 14: Airgun test carrier

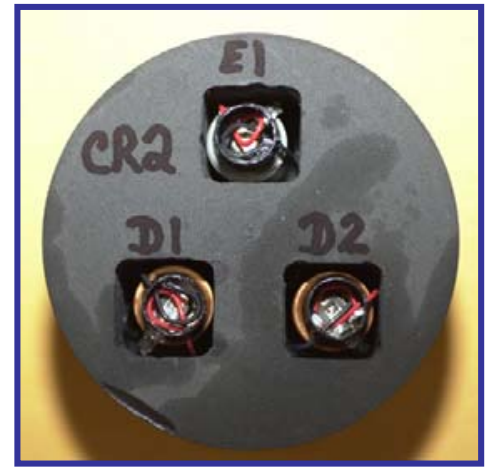

Figure 15: CR2 cells for Airgun testing 
Three tests were performed with target accelerations of $60 \mathrm{kG}$ 's for the first and $100 \mathrm{kG}$ 's for the second and third. Multiple CR2 cells were included in each test. Airgun data is in figure 16.

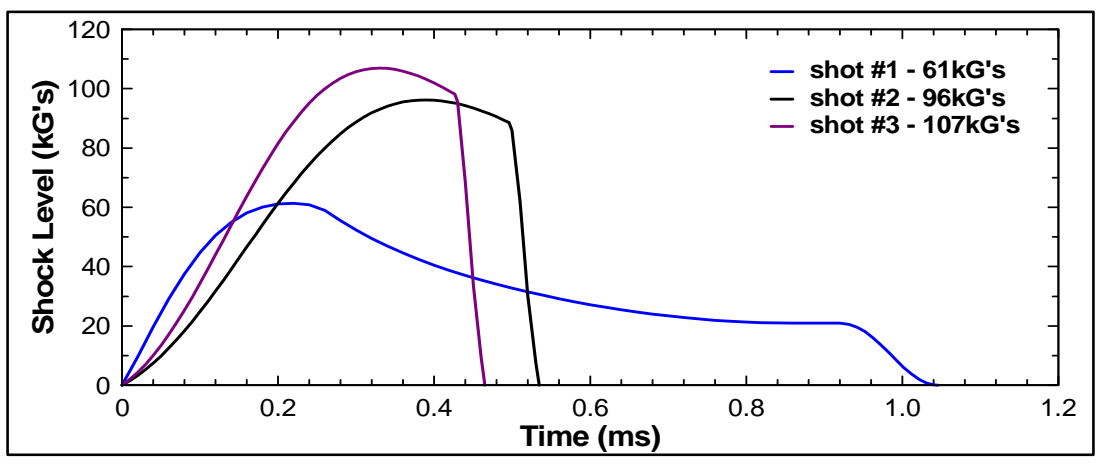

Figure 16: Airgun Acceleration Pulses

Airgun test results showed that while there were no failures during the $60 \mathrm{kG}$ test, the cells were definitely affected by the impact. Post shock discharge tests showed that the tested cells had discharge curves both shorter in runtime and lower in amplitude than that of the control cell. The only positive aspect of the $60 \mathrm{kG}$ results is that the shapes of the discharge curves are still representative of a typical discharge and the runtimes are also still of an acceptable length. However, given that the cells were indeed affected, it would appear that acceleration levels of $60 \mathrm{kG}$ 's would be the limit for these types of cells. This conclusion is further supported when looking at the results from the $100 \mathrm{kG}$ tests. In these cases, the post shock discharge curves no longer represent a typical discharge curve, which is a smooth, gradual decline. Runtimes for these cells are also greatly decreased and several cells were no longer functional post shock.

\begin{tabular}{|c|c|c|c|}
\hline Cell \# & $\begin{array}{c}\text { Open Circuit } \\
\text { Voltage } \\
\text { pre- } \\
\text { shock }\end{array}$ & $\begin{array}{c}\text { Post Shock } \\
\text { post } \\
\text { shock }\end{array}$ & $\begin{array}{c}\text { Runtime (min) } \\
\text { 500mA load to } \\
\text { 2V cutoff }\end{array}$ \\
\hline Shot \#1 - 61kG's \\
\hline D1 & 3.23 & 3.13 & 84.88 \\
\hline D2 & 3.23 & 3.21 & 82.00 \\
\hline shot \#2 - 96kG's \\
\hline D3 & 3.21 & 3.21 & 84.90 \\
\hline D4 & 3.22 & 3.22 & 66.37 \\
\hline shot \#3 - 107kG's \\
\hline D5 & 3.23 & 3.00 & 74.50 \\
\hline D6 & 3.22 & 0.54 & n/a \\
\hline
\end{tabular}

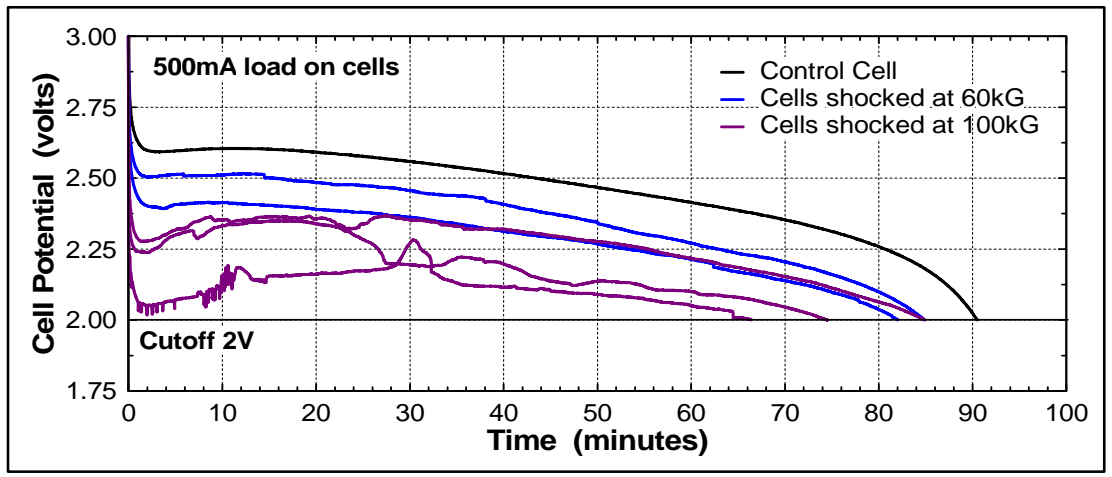

Table 4; Figure 17: Airgun test results for the DLCR2 cells

\begin{tabular}{|c|c|c|c|}
\hline \multirow{2}{*}{ Cell \# } & \multicolumn{2}{|c|}{$\begin{array}{l}\text { Open Circuit } \\
\text { Voltage }\end{array}$} & \multirow{2}{*}{$\begin{array}{l}\text { Post Shock } \\
\text { Runtime (min) } \\
500 \mathrm{~mA} \text { load to } \\
2 \mathrm{~V} \text { cutoff } \\
\end{array}$} \\
\hline & $\begin{array}{l}\text { pre- } \\
\text { shock }\end{array}$ & $\begin{array}{c}\text { post } \\
\text { shock }\end{array}$ & \\
\hline \multicolumn{4}{|c|}{ shot \#1-61kG's } \\
\hline E1 & 3.25 & 2.99 & 57.92 \\
\hline \multicolumn{4}{|c|}{ shot \#2 - 96kG's } \\
\hline E2 & 3.24 & 3.24 & 56.60 \\
\hline E3 & 3.24 & 3.24 & 80.80 \\
\hline \multicolumn{4}{|c|}{ shot \#3 - 107kG's } \\
\hline E4 & 3.25 & 3.25 & 0.00 \\
\hline E5 & 3.27 & 3.32 & 25.30 \\
\hline
\end{tabular}

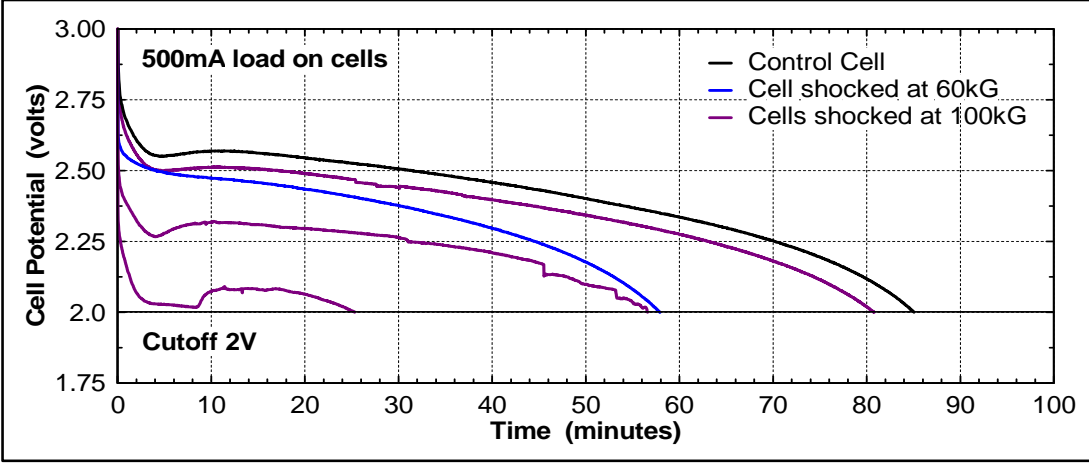

Table 5; Figure 18: Airgun test results for the EL1CR2 cells 


\section{SPIN TESTING}

In addition to the high levels of acceleration present in a ballistic environment, components also must be able to function and survive under high spin conditions. Spin rates from $60 \mathrm{~Hz}$ up to 300 $\mathrm{Hz}$ are commonplace and the CR2 cells must be able to survive if they are to be used in a ballistic telemetry system. A flight simulator, shown in figure 19, was used to test the CR2 cells at spin rates of 100, 200 and 225rps (revolutions per second). Each spin test included two DLCR2 cells and two EL1CR2 cells, shown in figure 20. The cells were positioned in a vertical orientation and placed at distances of 0.5 inches and 1.25 inches off center.

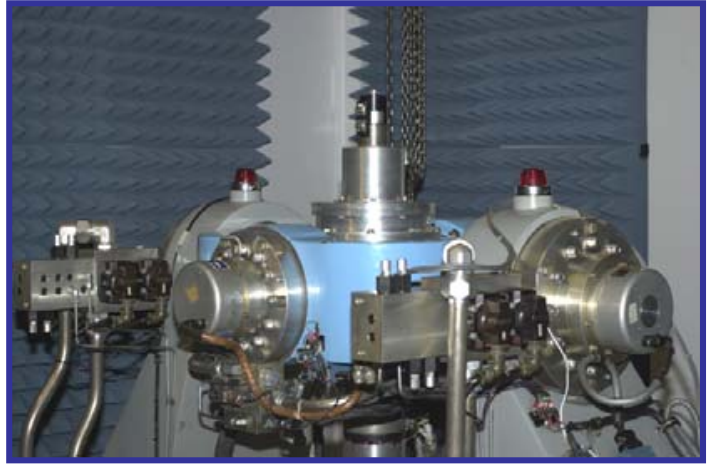

Figure 19: Flight Simulator

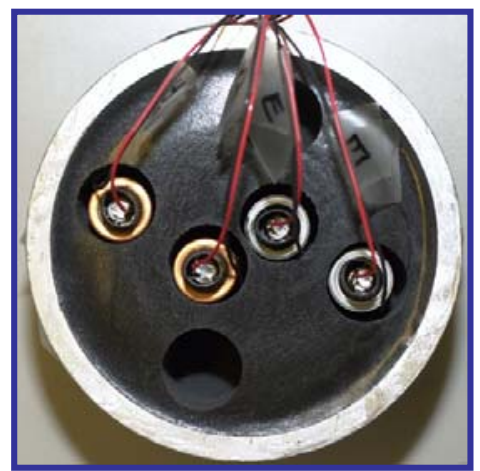

Figure 20: CR2 cells in spin fixture

During each test, the CR2 cells had a 500mA load applied to them and the output of each cell was recorded throughout the spin cycle. The output of a stationary control cell was also recorded. Results from these tests showed that the CR2 cells performed extremely well while under spin. A comparison of the test cells with the control cell shows that their outputs are almost identical throughout each test. The only major difference is that the test cells have a lower potential. This is most likely caused by the additional loading placed on the cells due to the slip ring and cabling. When the cells were discharged post spin, they produced runtimes in the range of 80 to 85 minutes and had discharge curves similar to that of an untested cell. These results show that the high spin had no lasting effect on the cells and little to no effect on the overall performance of the cells either during or after the spin event.

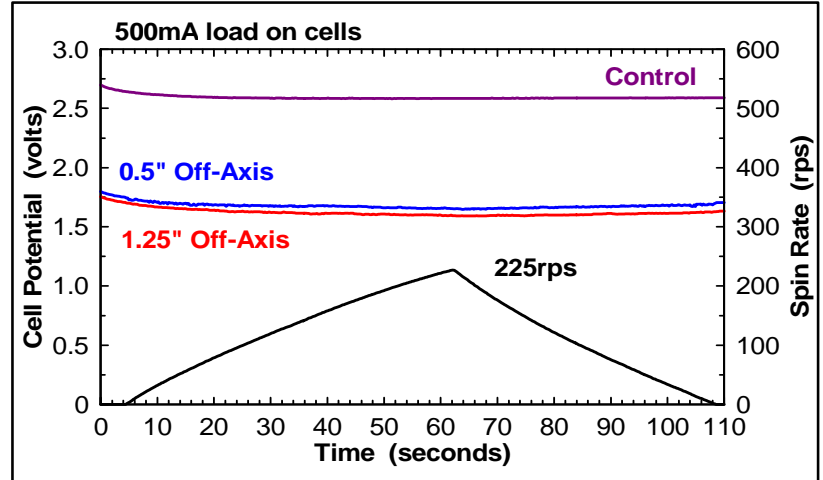

Figure 21: DLCR2 225rps spin test results

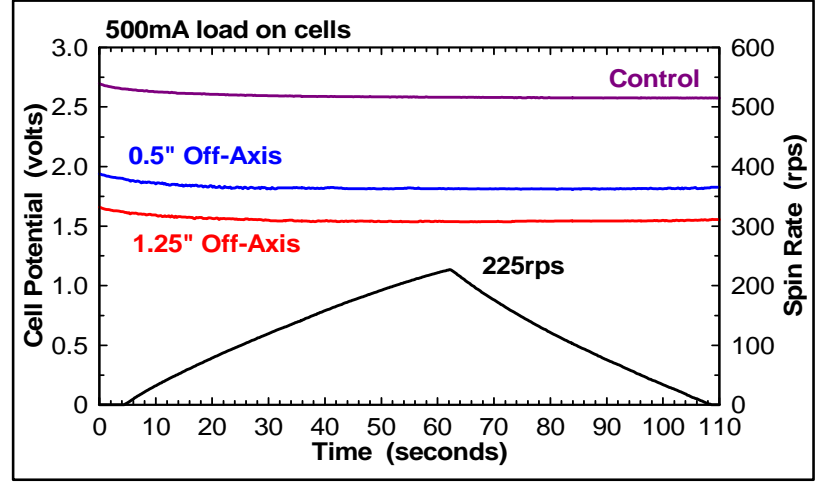

Figure 22: EL1CR2 225rps spin test results 


\section{INTEGRATION OF CR2 CELLS INTO BALLISTIC TELEMETRY SYSTEMS}

Based on the survivability and performance of the CR2 cells with respect to high levels of acceleration and spin, the CR2 cells have been integrated into several ballistic telemetry systems. One example is that of a NATO Standard Telemetry Fuze (NSTF). The NSTF is an on-board instrumentation system that replaces the standard NATO nose fuze with telemetry and sensors. This system uses multiple CR2 cells to power the on-board electronics. Preliminary qualifications of this system included flight tests in which the NSTF was attached and flown on a modified M831 projectile. Setback accelerations in the range of $20 \mathrm{kG}$ to $30 \mathrm{kG}$ were successfully recorded and no CR2 failures occurred.

Another system which has used the CR2 cell as a power supply is the Mortar Diagnostic Fuze (MDFuze), shown in figure 23. This system replaced the standard fuze with telemetry and sensors and was successfully flown on several $60 \mathrm{~mm}$ mortars. Setback accelerations around $7 \mathrm{kG}$ were seen for these tests and no CR2 failures were reported.

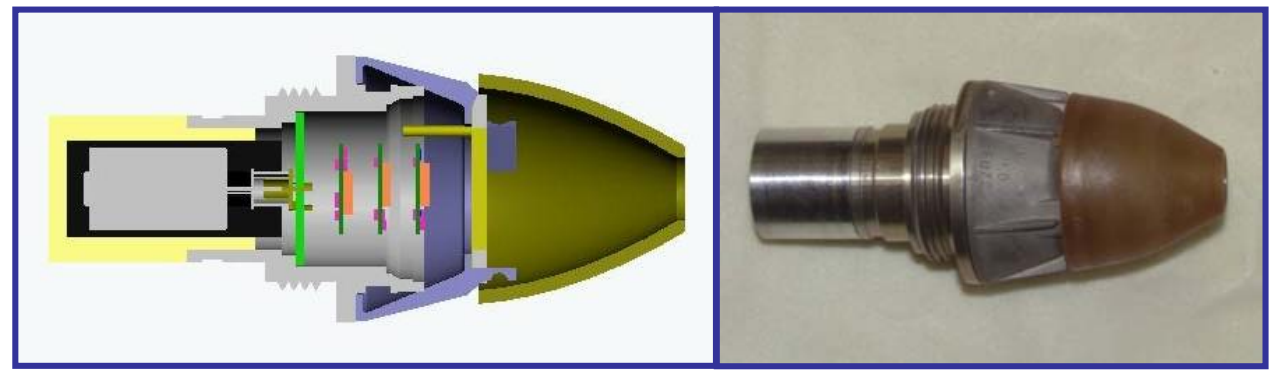

Figure 23: Mortar Diagnostic Fuze

A third system which has incorporated the CR2 as a power supply is the Telemetry Data Unit (TDU), shown in figure 24. This telemetry system is a stand alone unit which has been used to provide a variety of in-bore ballistic diagnostics. This system has been used to record and transmit setback accelerations from $20 \mathrm{kG}$ to $40 \mathrm{kG}$ in the ARL airgun. The system has also been used to provide in-bore pressure and set-back acceleration data for a modified M829A2 KE round. Tests using this type projectile produced setback accelerations around 50kG's. Once again, the system worked successfully and no CR2 failures were reported.

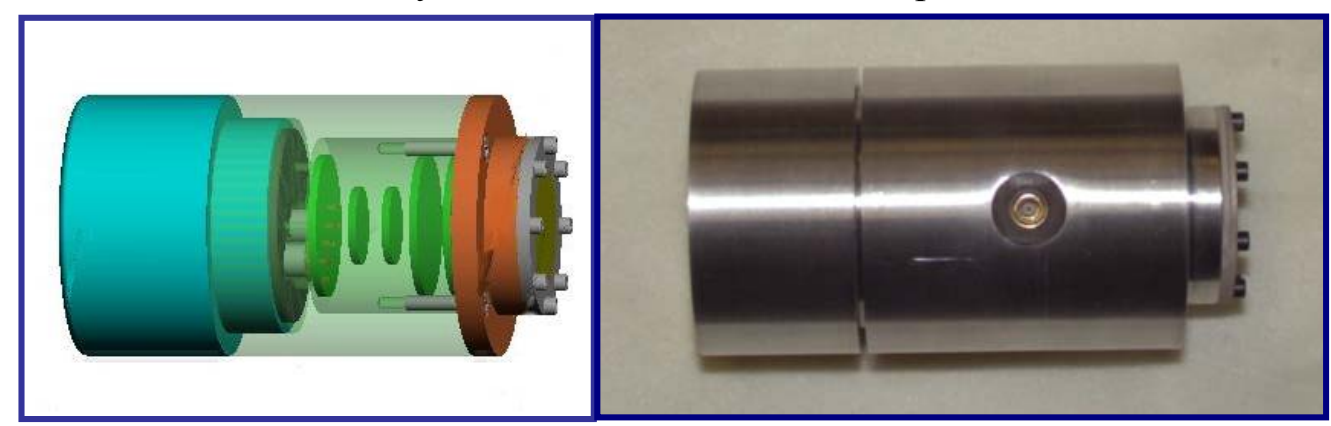

Figure 24: Telemetry Data Unit

The successful integration and implementation of the CR2 cells into these ballistic telemetry systems shows that these cells can indeed be used as a reliable power supply capable of withstanding harsh ballistic environments. 


\section{CONCLUSIONS}

The CR2 and 123 lithium manganese dioxide batteries were initially considered for integration into ballistic telemetry systems based on their availability, shelf life and high current capacities. Before these cells could be used however, it needed to be known whether or not they could both perform and survive under harsh conditions such as high set-back acceleration and high spin. Preliminary shock testing up to $35 \mathrm{kG}$ 's showed that the 123 cells can not survive a ballistic environment and that the CR2 cells can not only survive, but also provide the same electrical performance as that of an unshocked cell. Additional testing in both vertical and horizontal orientations produced similar results and reinforced the notion that these cells could be used in a ballistic telemetry system. However, once airgun testing was performed, it was discovered that these cells did have a limit as to how hard they could be hit. At accelerations up to $35 \mathrm{kG}$ 's, there were no major changes in performance. At accelerations around 60kG's, the cells survived but their performance was decreased. And at accelerations around 100kG's, the cells had major drops in performance and even some complete failures. These results show that use of these cells should be limited to a maximum within the $35 \mathrm{kG}$ to $60 \mathrm{kG}$ range. High spin testing at rates of 100, 200 and 225 revolutions per second showed that spin had little to no effect on the performance of the cells. The tested cells produced results almost identical to cells which had not been tested. Based on these test results, the CR2 cells have been integrated into several ballistic telemetry systems and used successfully without any failures. The culmination of all of this information gives the conclusion that the survivability and performance of the CR2 cells make them ideal for use in a variety of ballistic telemetry systems.

\section{REFERENCES}

Katulka, Gary; "Development of a Telemetry Data Unit (TDU) for In-bore Ballistic Diagnostics", US Army Research Laboratory, HSTSS Symposium, August 2003

Davis, Bradford; McMullen, Ken; "Development and Demonstration of a G-Hardened Inertial Sensor Suite and Mortar Diagnostic Fuze", ARL-TR-2918, US Army Research Laboratory, Aberdeen Proving Ground, MD, March 2003

Davis, Bradford; "NATO Standard Telemetry Fuze (NSTF) Performance Test Results", US Army Research Laboratory, Instrumentation for Testing Technical Symposium, August 2004

Stephan, David; "NATO Standard Telemetry Fuze (NSTF)", HSTSS Symposium, August 2003 